\title{
Determining 'curriculum viability' through standards and inhibitors of curriculum quality: a scoping review
}

\author{
Rehan Ahmed Khan ${ }^{1,2^{*}}$ (D) Annemarie Spruijt ${ }^{2,3}$ (D) Usman Mahboob ${ }^{4,5}$ (D) and Jeroen J. G. van Merrienboer ${ }^{2}$ (D)
}

\begin{abstract}
Background: A curriculum is dynamic entity and hence, metaphorically, can be considered 'alive'. Curricular diseases may impair its quality and hence its viability. The quality of a curriculum is typically assessed against certain quality standards only. This approach does not identify the inhibitors impeding the achievement of quality standards. The purpose of this study is to identify not only standards but also inhibitors of curriculum quality, allowing for a more comprehensive assessment of what we coin 'curriculum viability'.

Methods: We performed a scoping review of 'curriculum viability', after which 13 articles were found eligible through a meticulous search and selection process. We first identified 1233 studies based on matching keywords, title and abstract; 36 of which met our inclusion criteria. After application of the Qualsyst criteria, two independent reviewers performed a thematic analysis of the 13 articles that remained.
\end{abstract}

Results: While all studies reported on standards of quality, only two studies described both standards and inhibitors of quality. These standards and inhibitors were related to educational content and strategy, students, faculty, assessment, educational/work environment, communication, technology and leadership.

Conclusions: The framework of curriculum viability thus developed will help identify inhibitors adversely affecting the curriculum viability and remaining hidden or un-noticed when curriculum evaluation is done.

Keywords: Curriculum viability, Quality standards, Curricular problems, Curricular diseases, Curriculum evaluation, Inhibitors

\section{Background}

The curriculum has no universal definition. Curriculum theory describes the basis of its development. Its four main components are aims, contents, methods of teaching and evaluation [1]. This theory defines the basic structure of curriculum but with more research in education, anatomy of curriculum has expanded. Learning theories or paradigms have shaped the perspectives or models of curriculum from the beginning of last century. Behaviourist learning theories are based on response to a stimulus; cognitivist paradigms explain the

\footnotetext{
* Correspondence: rehan.ahmed@riphah.edu.pk

${ }^{1}$ Islamic International Medical College, Riphah International University, Al-Mizan IIMCT Complex, Old Supreme Court Building, 274 Peshawar Rd, Rawalpindi, Pakistan

${ }^{2}$ School of Health Professions Education, Maastricht University, Maastricht,

The Netherlands

Full list of author information is available at the end of the article
}

mind-memory phenomena whereas constructivist theory explains the buildup of knowledge on the previous knowledge [2]. Based on Skinners Behaviourist theory, Tyler in 1949 gave the prescriptive model of curricular development that comprises of educational purposes and experiences, structure and evaluation of the curriculum [3]. Hilda Taba in 1962 modified Tyler's model by producing an 'Interactive model, which comprised of more or less of the same components, however more emphasis was laid on learning and teaching and all components (objectives, contents, learning experiences, teaching strategies and evaluative measures) interacted with each other [4]. Walker in 1971 gave the process or descriptive model of curriculum development, which is also called naturalistic model. It was based on (i) Platform (beliefs that guide curriculum developer), (ii) Deliberation (process of making decisions) and (iii) Design (organisation and 
structure of the curriculum) [5]. In 1986 for undergraduate medical curricula, Harden devised ten questions, which guided the practical development of a curriculum [6]. Almost during the same time Mager stressed on the needs of defining the instructional objectives used in the curricula [7]. Gagne however had stressed in 1965 on 'conditions of learning' and ADDIE model in early 1980's emphasized the instructional design based on Analysis, Design, Develop, interaction and Evaluation [8]. J G van Merrienboer gave the $4 \mathrm{C}$ ID model explaining the learning of a task, based on learning and training phase with reflection and feedback as the corner stones [9].

With evolution of Curriculum, it can be viewed as a sophisticated blend of educational strategies, course content, learning outcomes, educational experiences, assessment, the educational environment, timetable and programme of work $[10,11]$. It becomes outdated or riddled with problems if not regularly reviewed and renewed [12]. Being a dynamic entity, the curriculum can be considered alive and, in its ideal state, healthy. In humans, the standard values for being non-diabetic are less than $125 \mathrm{mg} / \mathrm{dl}$ [13], which is one of the standards to be achieved to remain healthy. If such standard is not achieved, the person will become unhealthy (diabetic). Some factors may act as inhibitors to the healthy state in humans and contribute to diabetes such as: eating unhealthy food and lack of exercise. Continuing in this metaphorical vein, curricula are like humans. There are curricular inhibitors that may deter them to achieve certain expectations (standards). Relevant literature in curriculum evaluation and accreditation have more emphasis on two aspects, either on setting standards [14] and seeking evidence to confirm their fulfillments or on describing clinical pictures of some curricular diseases [15]. There is a need to explore the curricular dynamics and interplay of their elements and most importantly indicate the inhibitors that contribute to the morbidity of curricula.

The traditional approach to determine a curriculum's health condition is to evaluate its quality. Curriculum evaluation aims to determine the curriculum's quality by comparing it against different national or global accreditation quality standards [16]. These quality standards in medical education curricula, for example, serve as expectations and may include, but are not limited to, the World Federation of Medical Education (WFME) global standards for quality improvement; Liaison Committee for Medical Education (LCME) accreditation standards; and General Medical Council's (GMC) 'Tomorrow's doctor' standards [17-20]. In this approach, quality is synonymous with the attainment of standards [21], whether they are basic minimum standards or standards of excellence [22]. Consequently, the main emphasis is on defining quality, setting quality standards, comparing them with the outcomes, and on determining the extent to which standards have been met $[23,24]$.

The quality of curricula can be assessed in areas of mission and objectives, educational program, assessment, students, faculty, educational resources, program evaluation, governance and administration and continuous renewal [17]. Such quality assessment, however, does not aim to detect the inhibitors that potentially interfere with the attainment of quality standards, but only serves as a checklist of what is in order and what is not. Even if a school or agency does identify the inhibitors that impede the achievement of standards, it is not a structured process that has been described in the literature.

As such, insight into the degree to which quality standards have been met may not give a true reflection of a curriculum's health status. The curriculum may be meeting certain quality standards, but still be fraught with problems (inhibitors) that remain unnoticed without a purposeful effort to detect them [15].

That said, we can identify two approaches in curriculum evaluation, namely: the reviewers' approach, which aims to provide a report on the current status of the curriculum against certain standards in a judgmental perspective, and the interpreters' approach, which investigates why standards have (or have not) been met in a more analytical stance. Reviewers need only standards and evidence from practice to decide, while interpreters need to study the underlying variables that contribute to the current state of the curriculum. Interpreters are like doctors of the curriculum; they gather information to diagnose the condition from different sources.

Curriculum evaluation is done by reviewers, while we would like to introduce a new term that best suit the job of the interpreters: 'Curriculum viability', which is the current state of a curriculum determined by the degree to which particular quality standards have or have not been met, and inhibitors affecting the attainment of those standards. Hence, measures of viability will yield added information that is more valuable for renewal and improvement than quality measures alone. Figure 1 shows the difference in approach and outcome of curriculum evaluation and curriculum viability.

The allusion to these inhibitors is not completely new as Abrahamson in 1978 had already identified 'Diseases of the Curriculum' and the problems (inhibitors) responsible for them. He described nine diseases in total, along with the underlying problems in some diseases. While revisiting this iconic article, we can clearly identify some inhibitors that would help curriculum interpreters. For instance, curriculo-sclerosis is extreme departmentalization due to extreme ownership of the subject and fighting for the hours of the discipline. Curriculum carcinoma is 


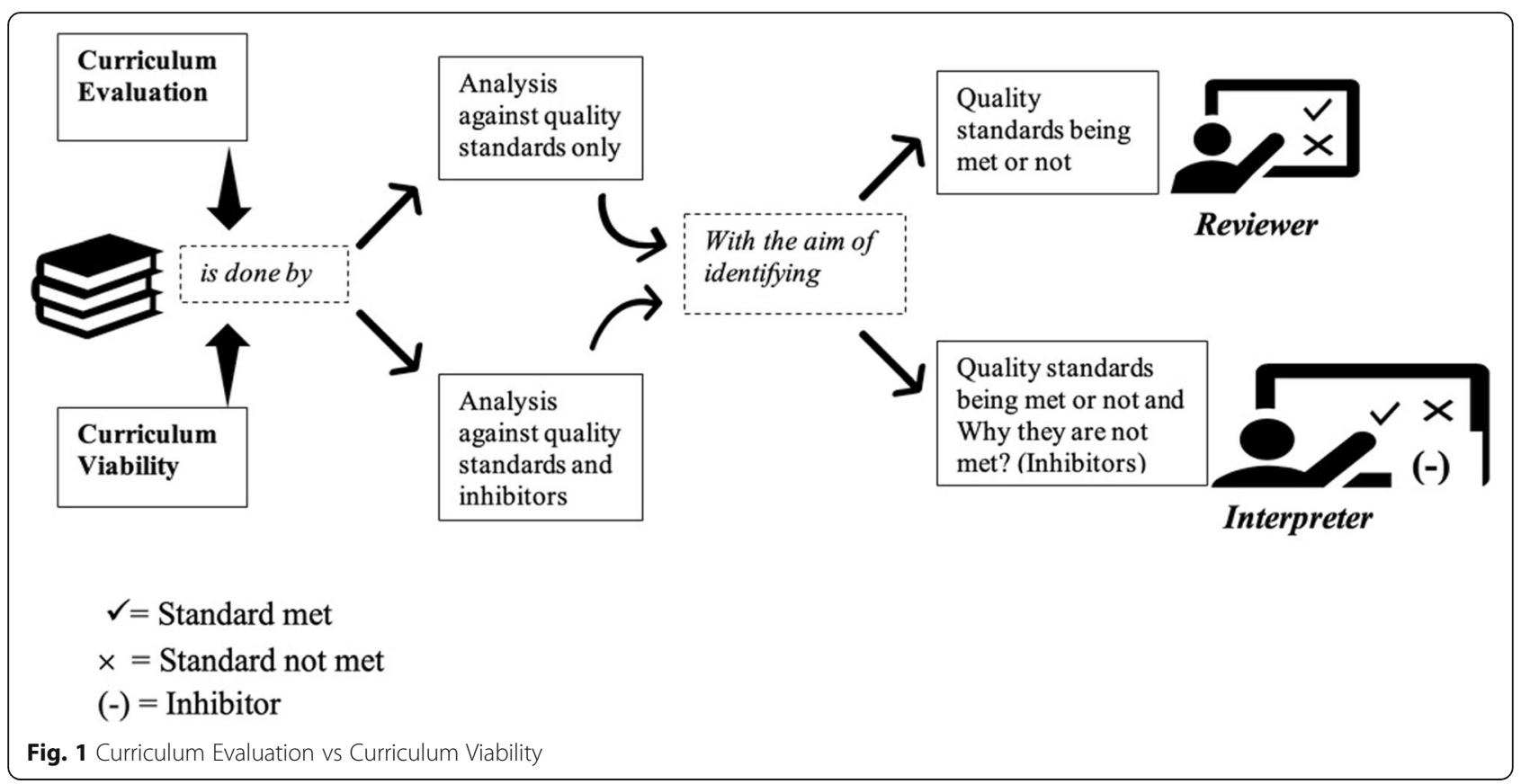

curriculum imbalance due to overgrowth of a particular curriculum segment by the disparity in the powerbase of one or more disciplines. Curriculo-arthritis is the miscommunication between disciplines due to limited opportunities for faculty members to meet and interact. Iatrogenic curriculitis is the excessive tampering with the curriculum due to abrupt and unplanned response to adjust or modify changes according to meet societal demands and expectations.

The above inhibitors clearly affect a curriculum's viability or well-being, yet they are not considered as part of regular curriculum evaluations based on specific standards $[16,17,25]$. Sometimes the effect of inhibitors on the curriculum viability is not linear or straightforward. For instance, when faculty members resist change, this may not directly compromise curriculum quality, but it could hinder the implementation of new ideas, thereby indirectly affecting future curriculum reforms. Adding more sophistication, one inhibitor (e.g., ineffective communication among faculty members) may compromise different aspects of curriculum viability and contribute to different manifestations simultaneously.

In summary, we postulate that curriculum viability provides a better foundation for evaluation and improvement than do traditional quality measures and also provides a basis for preventive measures. In the current study, we planned to conduct a scoping review to provide a quick overview to identify not only standards, but also inhibitors of curriculum quality, thereby allowing for a more comprehensive assessment of curriculum viability. The study aims to address two research questions: [1] What, according to the literature, are standards of curriculum quality? [2] What inhibitors of curriculum quality, have been reported in the literature?

\section{Methods}

\section{Search strategy}

We have used scoping review as a search strategy as it is of particular use when the topic has not yet been extensively reviewed or is of a complex nature. The purpose of a scoping review is to map the body of literature on a topic area to clarifying definition and conceptual boundaries of topic or field. It shares a number of the same processes as systematic reviews as they both use rigorous and transparent methods to identify and analyze all the relevant literature [26]. Curriculum viability is a new concept, hence we selected scoping review as our methodology.

We started the scoping review by identifying and scrutinising the problem, assembling the review team and formulating research questions using Arksey O'Malley framework of scoping review [27]. Consequently, we developed a methodological and systematic search strategy by defining key terms and selecting relevant databases for our literature search. We used Web of Science (WOS) using its three data bases namely (i) Web of Science core collection, (ii) MEDLINE, (iii) SciELO citation Index. Web of Science core collection further consists of six online databases which are (i) Science Citation Index Expanded, (ii) Social Science Citation Index, (iii) Arts and Humanities Citation Index, (iv) Emerging Sources Citation Index, (v) Book Citation Index and (vi) Conference Proceedings Citation Index. So, total of eight databases were accessed through WOS. 
Another reason to use Web of Science was that search results are reproducible and reportable, and it contains high quality peer reviewed journals. Google Scholar was used to search for grey literature so that information that is yet to be peer reviewed is known to the researchers and also to double check that no relevant article is missed that was searched through Web of Science [28]. Other search strategies used to identify articles of interest were a manual literature search, snowballing and seeking expert help [29].

\section{Key terms used}

To identify relevant studies, we used the key terms 'curriculum', 'viability', 'quality', 'indicators', 'education', 'evaluation', 'issues', 'diseases', 'inhibitors', 'standards and tools', in addition to the synonyms 'syllabus', 'excellence', 'marker', 'teaching and learning', 'problems' and 'instruments. This yielded too many results, majority of which were not relevant to 'curriculum viability'. The scope of search was kept broad to include the complete breadth of the topic. For this synonymous terms and Boolean Operator 'OR' was used. We used iterative search strategy combining different key terms to find the most relevant studies. Boolean Operator 'AND' was used to increase the relevance of results and to narrow them down. The details of the results of key terms and Boolean operators is given in Additional file 1.

In summary, we employed Boolean operators in concatenations of multiple keywords as in: (Curriculum OR Educational Programme OR Syllabus OR Course) AND (Indicators OR Standards) AND (Quality OR Excellence) AND (Problems OR Issues OR diseases OR Inhibitors).

\section{Studies selected}

The article selection process is presented in Fig. 2 and consisted of the following four phases: [1] identification, [2] screening, [3] determining eligibility, and [4] final inclusion of articles in the scoping review.

In the first phase, the lead author (RAK) identified a total of 1233 records after searching the literature for studies whose keywords, titles and abstracts matched the keywords -or combinations thereof- entered. The selection process and details were shared with the team and verified by three authors (RAK, AS \& UM). We consequently applied inclusion and exclusion criteria (Table 1) and removed duplicates in the screening phase, after which 36 full-text articles remained. In the eligibility phase, these articles were read using the validated Qualsyst checklist (by RAK and UM) to assess the quality of both quantitative and qualitative studies [30], the former containing 14, and the latter comprising 10 criteria. We scored each item on a 3-point scale $(0=$ No, $1=$ Partial, $2=$ Yes) with a maximum attainable score of
28 for the quantitative and of 20 for the qualitative studies. The final score was derived by dividing the total score by either 28 or 20 or as applicable. Consistent with Kmet, Lee and Cook's (2004) approach, we flagged a final score of $>80 \%$ as high, $71-79 \%$ as good, $50-70 \%$ as sufficient, and $<50 \%$ as limited quality. The cutoff point to include the studies in the scoping review was decided as $>50 \%$. Thirteen articles found to be of sufficient to good quality, published in the last 25 years (from 1992 to 2017), were included in the scoping review. The interrater agreement using Cohen's Kappa [31] was found to be 0.682 , which is considered to be a good agreement (Additional file 2).

\section{Data analysis}

Two authors (RAK and AS) read the 13 articles and performed a thematic analysis of the data [32]. They first used open coding to identify standards as well as inhibitors of quality, before proceeding to axial and selective coding in order to find relationships and commonalities between codes and generate themes and subthemes.

\section{Results}

The 13 articles of sufficient to good quality finally included in the scoping review consisted of realist reviews, mixed-methods research studies, archival research, evaluation research and descriptive surveys. These articles are subsumed in Tables 2 and 3. While 11 articles specifically focused on standards of curriculum quality (Table 2), answering our first research question, only two articles covered inhibitors affecting curriculum quality (Table 3), touching upon our second research question. More specifically as is evident from Table 2, articles 1-2 discussed quality indicators for distance learning; articles 3-5 addressed quality, quality culture and quality assurance of the curriculum; article 6 concentrated on the quality of the educational environment; and articles 7-11 looked into the assessment of curriculum quality based on global WFME quality standards. Articles 1-2 in Table 3, on the other hand, specifically dealt with inhibitors of curriculum quality.

Correspondingly, two main themes emerged from the thematic analysis of these 13 articles: 'Standards of curriculum quality' and 'inhibitors of curriculum quality' addressing curriculum viability. These two themes, moreover, spanned eight subthemes or areas affecting the quality of the curriculum, specifically: 1) educational strategy and content, 2) students, 3) faculty, 4) assessment, 5) educational environment, 6) curricular communication, 7) technology, and 8) leadership. Based on these results, we created a framework to assess curriculum viability (Table 4). 


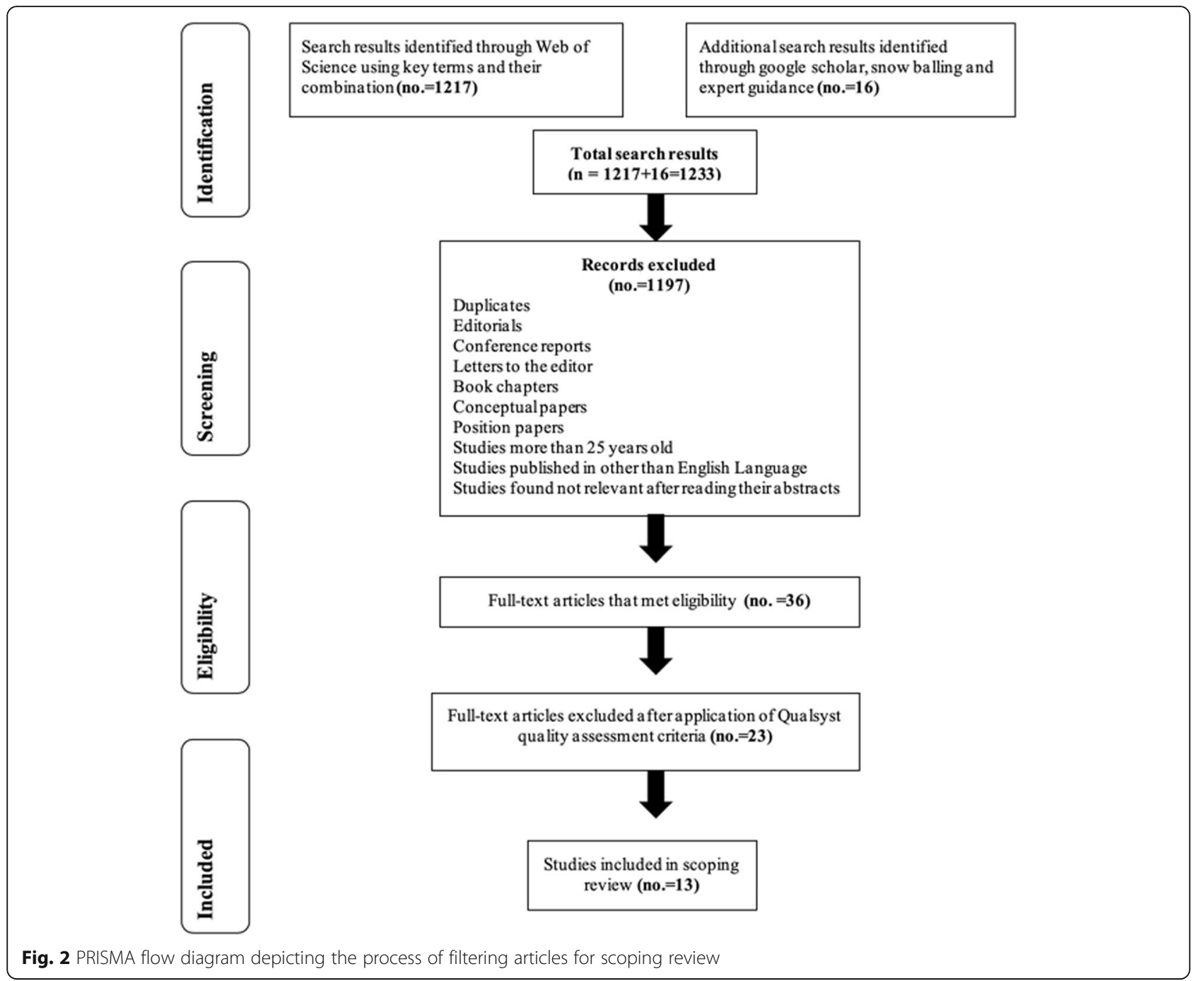

Theme 1: standards of curriculum quality

An analysis of the literature unearthed several factors that promote curriculum quality. Standards of a sound educational strategy and content contributing to curriculum quality were the presence of a robust and relevant mission and related objectives [35, 39, 41], a proper design, availability of instructional development and implementation guidelines, and regular

Table 1 Inclusion and exclusion criteria

\begin{tabular}{ll}
\hline Inclusion criteria & Exclusion criteria \\
\hline - Original research articles and systematic reviews & - Abstracts only \\
- Studies found through Web of Science & - Citations only \\
- Studies published in last 25 years & - Editorials \\
(from 1992 to 2017) & - Conference reports \\
- Studies related to educational research only & - Letters to the editor \\
- Studies published in English language only & - Book chapters \\
- Grey literature & - Conceptual papers \\
- Studies found through manual search & - Position papers \\
and snowballing & \\
\hline
\end{tabular}

reviews of instructional materials [33]. Students also played an important role in determining curriculum quality, with their perceptions of teaching, teachers, educational atmosphere, academic self-perception and social self-perception bearing a positive relationship to the quality of the educational environment [38]. Involving students in the organisation's decision-making processes, evaluating academic programmes [37], letting them use active learning techniques in the case of distance learning programmes [33], and allowing them sufficient protected time [43] were all factors conducive to quality. In a similar fashion, involving faculty in multiple roles, organisational decision-making [42] and in regular faculty development activities, and acquainting them with new teaching methods helped boost the quality of the curriculum. Also, teachers who respected their students' different learning approaches were important contributors to curriculum quality [17]. 
Table 2 Standards of curriculum quality as reported in the literature

\begin{tabular}{|c|c|}
\hline Article & Standards of Curriculum Quality (key findings) \\
\hline 1. A Primer on Quality Indicators of Distance Education [33] & $\begin{array}{l}\text { - Prompt feedback } \\
\text { - Student support services } \\
\text { - Programme evaluation and assessment } \\
\text { - Clear analysis of audience } \\
\text { - Documented technology plan } \\
\text { - Course structure guidelines } \\
\text { - Active learning techniques } \\
\text { - Respect for diverse learning styles } \\
\text { - Faculty support services } \\
\text { - Strong rationale for distance education that } \\
\text { correlates to the mission of the institution } \\
\text { - Appropriate tools and media } \\
\text { - Reliability of technology } \\
\text { - Course structure guidelines } \\
\text { - Implementation of guidelines for course development } \\
\text { - Review of instructional materials } \\
\text { - Institutional support and services }\end{array}$ \\
\hline $\begin{array}{l}\text { 2. Developing of indicators of an e-learning benchmarking model } \\
\text { for higher education institutions [34] }\end{array}$ & $\begin{array}{l}\text { - Institution and organisation } \\
\text { - Curriculum and instructional design } \\
\text { - Resources and information technology } \\
\text { - Learning and teaching } \\
\text { - Learner faculties and supporting personnel } \\
\text { - Measurement and evaluation }\end{array}$ \\
\hline $\begin{array}{l}\text { 3. Understanding Quality Culture in Assuring Learning at Higher } \\
\text { Education Institutions [35] }\end{array}$ & $\begin{array}{l}\text { - Development of a relevant mission and vision } \\
\text { - Achievement of internal/external standards and goals } \\
\text { - Procurement of resources for optimal institutional functioning } \\
\text { - Degree to which student complaints are addressed } \\
\text { - Competence of instructors } \\
\text { - Student engagement with faculty, staff and administration }\end{array}$ \\
\hline $\begin{array}{l}\text { 4. Counting quality because quality counts: differing standards in } \\
\text { master's in medical education programme [36] }\end{array}$ & $\begin{array}{l}\text { - Modality, time frame and core teaching team of the } \\
\text { taught component } \\
\text { - Length of programme } \\
\text { - Length of dissertation and time allotted for its completion }\end{array}$ \\
\hline 5. Quality Assurance in Higher Education: A Review of Literature [37] & $\begin{array}{l}\text { - Involvement of students in quality assurance process: } \\
\text { student's evaluation of academic programmes } \\
\text { - Faculty-student interaction }\end{array}$ \\
\hline $\begin{array}{l}\text { 6. Development and validation of the Dundee Ready Education } \\
\text { Environment Measure (DREEM) [38] }\end{array}$ & $\begin{array}{l}\text { - Students' perceptions of teaching } \\
\text { - Students' perceptions of teachers } \\
\text { - Students' perceptions of atmosphere } \\
\text { - Students' academic self-perception } \\
\text { - Students' social self-perception }\end{array}$ \\
\hline $\begin{array}{l}\text { 7. Designing an evaluation framework for WFME basic standards for } \\
\text { medical education [14] } \\
\text { 8. Preparing for an institutional self-review using the WFME standards } \\
\text { - An International Medical School case study [17] } \\
\text { 9. Evidence-based postgraduate training. A systematic review of reviews } \\
\text { based on the WFME quality framework [39] } \\
\text { 10. Evaluating a master of medical education programme: Attaining } \\
\text { minimum quality standards? [40] } \\
\text { 11. The importance of medical education accreditation standards [41] }\end{array}$ & $\begin{array}{l}\text { - Mission and objectives } \\
\text { - Educational programme } \\
\text { - Assessment of students } \\
\text { - Students } \\
\text { - Academic staff/faculty } \\
\text { - Educational resources } \\
\text { - Programme evaluation } \\
\text { - Governance and administration } \\
\text { - Continuous renewal }\end{array}$ \\
\hline
\end{tabular}

In the area of student assessment, provision of prompt feedback raised curriculum quality by affording students the opportunity to become aware of their shortcomings and improve themselves [34]. The environment too, could be beneficial when learner-centred as this increased learning opportunities for students [43]; and in the case of the work environment, when characterised by a flexible and people-oriented culture, a climate of trust, and a shared understanding among faculty and support staff of educational principles used in the curriculum [42]. Other quality-enhancing factors were proper communication of the curriculum to stakeholders which increased its effectiveness [39, 42], use of reliable technology underpinned by a well-documented technology plan, and selection and use of appropriate tools and media in the case of distancebased learning [33]. Finally, effective leadership could drive curriculum quality, with leaders having the multifaceted capacity to create partnerships, allocate resources, influence people, process management, optimise institutional functioning and achieve standards and goals [42]. 
Table 3 Indicators of curriculum viability, comprising standards as well as inhibitors of curriculum quality, that have been reported in the literature

\begin{tabular}{|c|c|}
\hline Article & Curriculum viability indicators \\
\hline 1. Unravelling quality culture in higher education: a realist review [42] & $\begin{array}{l}\text { Standards of Curriculum quality } \\
\text { - Strategy for continuous improvement } \\
\text { - Quality management systems } \\
\text { - Staff and student involvement in organisational decision-making } \\
\text { - Consideration of evolving student demands } \\
\text { - Clear policies, procedures, systems, responsibilities } \\
\text { - Flexible, people-oriented cultures } \\
\text { - Presence of various cultures } \\
\text { - Shared (educational) quality values } \\
\text { - Leadership commitment and skills } \\
\text { - Allocation of resources } \\
\text { - Creation of partnerships, leaders' ability to influence people and process } \\
\text { management } \\
\text { - Creation of climate of trust and sharedunderstanding } \\
\text { - Ability to perform multiple roles } \\
\text { - Setting and communication of policies } \\
\text { - Communication/information for quality } \\
\text { - Provision of information on strategies and policies } \\
\text { - Clear task requirements and responsibilities } \\
\text { Inhibitors of Curriculum quality } \\
\text { - Lack of staff and student involvement in organisational decision-making } \\
\text { - Failure to respond to evolving student demands } \\
\text { - Lack of policies, procedures, systems, responsibilities } \\
\text { - Lack of resources } \\
\text { - Rigid, control-oriented cultures } \\
\text { - Top-down approaches to quality management implementation } \\
\text { - Presence of strong disciplinary cultures } \\
\text { - Research culture that undervalues education } \\
\text { - Focus on inspection and control } \\
\text { - Leaders acting as information gatekeepers } \\
\text { - No/insufficient sharing of best practices across the organisation } \\
\text { - Lack of appropriate communication channels }\end{array}$ \\
\hline $\begin{array}{l}\text { 2. Implementing an online curriculum for medical education: examining } \\
\text { the critical factors for success [43] }\end{array}$ & $\begin{array}{l}\text { Standards of Curriculum Quality } \\
\text { - Curriculum design } \\
\text { - Instructional feedback } \\
\text { - Curriculum implementation } \\
\text { - Media features } \\
\text { - Integration } \\
\text { - Time } \\
\text { - Learner-centred environment } \\
\text { Inhibitors of Curriculum quality } \\
\text { - Inappropriate level of curriculum content } \\
\text { - Low-quality quizzes } \\
\text { - Technological barriers } \\
\text { - User interface barriers } \\
\text { - Low-quality integration } \\
\text { - Perceived lack of sufficient time } \\
\text { - Trainee resistance to new curriculum } \\
\text { - Lack of social interaction }\end{array}$ \\
\hline
\end{tabular}

\section{Theme 2: inhibitors of curriculum quality addressing curriculum viability}

As briefly touched upon previously, only Bendermacher et al. [42] and Olson et al. [43] (Table 3) described both standards and inhibitors of curriculum quality, thereby addressing curriculum viability and answering our second research question. While Bendermacher et al. specifically focused on the organisational context elements such as communication and leadership that impact quality culture, Olson et al. explored standards and inhibitors from a distance education perspective.
Addressing the quality inhibitors, the first ones we encountered in the area of educational strategy and content were inappropriate content and a low level of integration preventing the proper utilisation of curriculum contents [43]. Moreover, little social interaction and students' resistance to curriculum renewal, acted as barriers to learning. Further undermining curriculum quality, by detrimentally affecting quality culture, was a failure to respond to evolving student demands [42]. In distance learning programmes, a perceived lack of sufficient time caused by excessive service obligations, a lack 
Table 4 Framework for Assessing Curriculum Viability (Designed based on results of Tables 2 and 3)

\begin{tabular}{|c|c|c|}
\hline Area & Standards & Inhibitors \\
\hline Educational Strategy & $\begin{array}{l}\text { 1. Development of relevant Mission and Objectives } \\
\text { 2. Curriculum design } \\
\text { 3. Length of program } \\
\text { 4. Implementation guidelines } \\
\text { 5. Review of instructional material }\end{array}$ & $\begin{array}{l}\text { 1. Low quality integration } \\
\text { 2. In appropriate curriculum content level }\end{array}$ \\
\hline Students & $\begin{array}{l}\text { 6. Perception of teaching } \\
\text { 7. Perception of teachers } \\
\text { 8. Perception of atmosphere } \\
\text { 9. Academic self-perception } \\
\text { 10. Social self-perception } \\
\text { 11. Student support services } \\
\text { 12. Student engagement with faculty, staff and } \\
\text { administration } \\
\text { 13. Degree to which student complaints are addressed } \\
\text { 14. Active learning techniques } \\
\text { 15. Clear analysis of audience }\end{array}$ & $\begin{array}{l}\text { 3. Lack of time for sufficient studying } \\
\text { 4. Neglecting Student demands } \\
\text { 5. Student's resistance to new curriculum }\end{array}$ \\
\hline Faculty & $\begin{array}{l}\text { 16. Ability to perform multiple roles } \\
\text { 17. Competence of instructors } \\
\text { 18. Staff involvement in organizational decision making } \\
\text { 19. Faculty Development } \\
\text { 20. Respect Diverse ways of learning }\end{array}$ & $\begin{array}{l}\text { 6. Lack of staff involvement in organizational } \\
\text { decision making }\end{array}$ \\
\hline Assessment & $\begin{array}{l}\text { 21. Prompt feedback } \\
\text { 22. Measurement and Evaluation }\end{array}$ & 7. Low quality quizzes \\
\hline $\begin{array}{l}\text { Educational and working } \\
\text { Environment }\end{array}$ & $\begin{array}{l}\text { 23. Flexible people-oriented culture } \\
\text { 24. Presence of various cultures } \\
\text { 25. Climate of trust and shared understanding } \\
\text { 26. Learner centered environment }\end{array}$ & $\begin{array}{l}\text { 8. Rigid, control-oriented cultures } \\
\text { 9. Presence of strong disciplinary cultures } \\
\text { 10. Research culture undervaluing education }\end{array}$ \\
\hline Communication & $\begin{array}{l}\text { 27. Communicating policies and strategies } \\
\text { 28. Communication/Information for quality }\end{array}$ & $\begin{array}{l}\text { 11. Lack of sharing best practices across the } \\
\text { organization } \\
\text { 12. Lack of appropriate communication channels } \\
\text { 13. Lack of social interaction }\end{array}$ \\
\hline Technology & $\begin{array}{l}\text { 29. Documented technology plan } \\
\text { 30. Appropriate tools and media } \\
\text { 31. Reliability of technology } \\
\text { 32. Resources and information of technology }\end{array}$ & $\begin{array}{l}\text { 14. Technology Barriers } \\
\text { 15. User interface Barriers }\end{array}$ \\
\hline Leadership & $\begin{array}{l}\text { 33. Create partnerships } \\
\text { 34. Influence people management } \\
\text { 35. Achieving internal/external standards and goals } \\
\text { 36. Procuring resources for optimal institutional } \\
\text { functioning } \\
\text { 37. Allocate resources }\end{array}$ & $\begin{array}{l}\text { 16. Lack of policies, procedures, systems and } \\
\text { responsibilities } \\
\text { 17. Lack of resources } \\
\text { 18. Acting as communication gatekeepers } \\
\text { 19. Focus on inspection and control }\end{array}$ \\
\hline
\end{tabular}

of protected time and infringes on personal time all compromised curriculum quality [43]. Other impediments to curriculum quality were the exclusion of faculty from organisational decision-making [42] and an unfavourable educational/work environment. The latter denotes a rigid, control-oriented and disciplinary culture and a research culture that undervalues education [42].

While weak communication channels and lack of sharing of best practices across the organisation obscured the attainment of good curriculum quality [42], technological hindrances, such as software problems during video-enhanced lectures and insufficient computer access at work did the same in the case of distance learning programmes [43]. To end, ineffective leadership could adversely affect the quality of the curriculum, which was the case when educational leaders failed to establish clear policies, procedures, systems, resources and a distribution of responsibilities, and/or acted as communication gatekeepers who focused on inspection and control only [42].

\section{Discussion}

The purpose of the present scoping review was to identify standards and inhibitors of curriculum quality to assess curriculum viability. Since the assessment of a curriculum's viability requires knowledge of both standards and inhibitors of curriculum quality, we made an effort to find articles that described both elements. We found 13 studies in total of which only two studies [42, 43] fully met this criterion, although they did not specifically refer to these factors as assessing curriculum viability. 
In our quest for standards of curriculum quality that would answer our first research question, we found different definitions and explanations of such standards in the research literature. Different quality standards appeared to exist, but the ones most often cited in the papers we reviewed, were the widely accepted WFME global standards, which are structured according to nine broad areas of curriculum quality [22]. Although these standards enjoy wide currency and offer a holistic representation of quality, many find them difficult to interpret and use [14]. Another disadvantage is that they make no reference whatsoever to the inhibitors potentially affecting the curriculum quality. Next, a few papers included in our scoping review specifically addressed quality standards for distance learning curricula [33, 34, 43]. Comparison of the quality standards for distance-based curricula with those of their campus-based counterparts led us to conclude that the former, albeit sparse, varied and less structured, harboured the additional quality areas of 'technology' and 'protected time'.

As previously mentioned, Bendermacher et al. [42] and Olson et al. [43] provided an indirect answer to our second research question. In their realist review, Bendermacher et al. described the organisational context elements that inhibit quality culture. Organisational context is one of the areas that affects the curriculum quality. Harden in 1986, in his 'Ten Questions' also describes 'Organisation of the curriculum' as one of the questions to be answered while developing the curriculum [6]. Regarding organizational context, leadership and communication are important areas [17], without which successful implementation of curriculum is not possible as they affect the quality of curriculum directly. Related to this, Bendermacher et al. have described the inhibiting elements related to ineffective leadership, lack of student and staff involvement, insufficient resources, a rigid culture and poor communication. Olson et al. on the other hand, only addressed quality determinants pertaining to distance learning.

While it is true that reference to inhibitors related to the development, integration, content and communication of curricula is not new [15], we did not find any recent literature on viability indicators that combined standards and inhibitors of curriculum quality in the areas of 'mission and objectives', 'faculty development', 'student assessment', 'student support', 'governance', 'programme evaluation' and 'curriculum renewal'. Early detection of inhibitors in these areas may help prevent a curricular catastrophe from developing. Since prevention is better than cure, any curriculum assessment should not neglect to identify the inhibitors that potentially deter the attainment of desired standards.
Based on the results previously outlined, we developed a framework for curriculum viability (Table 4) that combines 37 standards and 19 inhibitors. Taken together, standards and inhibitors can be considered as 'indicators of curriculum viability'. They have been divided among the eight subthemes or areas affecting the quality of a curriculum, namely: educational strategy/content, students, faculty, assessment, educational/work environment, curriculum communication, technology and leadership. The areas identified are comparable to components of the curriculum as reported in literature $[6,17,44]$ and closely matches the WFME standards that have wider acceptance and used in undergraduate medical curriculum [14]. This would help the evaluators to use a familiar process of evaluation.

Inhibitors against standards have been scantly reported in the literature; hence our curriculum viability framework has only considered those standards against which inhibitors were reported directly or indirectly in an impact factor journal. This is being reflected in the framework where there are greater numbers of standards in one area than in another area, and the same is true for inhibitors.

Curriculum viability framework will enable the evaluators to assess the curriculum not only for standards but for inhibitors as well. This will help them link the existing inhibitors that may be impeding the achievement of curriculum standards and also provide the 'prophylaxis' to avoid the development of issues in the curriculum. It will also support the process of curriculum mapping, which is an effective way to find the gaps between the developed (the designed or the official curriculum), implemented (functional or the taught curriculum) and the learned (assessed) curriculum. Mapping identifies the gaps between these phases of curriculum by establishing, relating and analyzing links between different components of the curriculum [45]. However, it does not explicitly find the reasons behind these gaps. Using the curriculum viability framework alongside the mapping process, it will help the curriculum expert to look for gaps in different areas where inhibitors have already been identified.

The framework is mainly intended towards interpreters who aim to find possible causes of an 'unhealthy curriculum'; either to prevent it from the disease or cure it. For instance, 'students' resistance to new curriculum' will not only explain the impediment of achievement of standards in the area of 'students', such as 'lack of student engagement with faculty', but it may also effect other areas such as 'assessment'. Hence the inhibitors may not only be interpreted against their standards but also as stand-alone problems that may afflict any area of the curriculum. The timely identification of these inhibitors prevents the curriculum from becoming less viable or non-viable. 


\section{Limitations}

One of the limitations of this study is that we were unable to establish links between standards and inhibitors of curriculum quality in a holistic fashion. This is because the literature on inhibitors of curriculum quality was scant. However, our analysis of the literature did result in a framework presenting indicators of curriculum viability that embraces both standards and inhibitors. This framework as depicted in Table 4 may guide the further exploration of inhibitors in curriculum areas hitherto uninspected, that potentially explain why particular standards have not been met. The second limitation was that we searched for English-language articles only, meaning that we may have missed some studies on curriculum quality and viability written in other languages.

\section{Future recommendations}

Curriculum issues can be diagnosed using different techniques, models and tools. These may include Harden's Ten Questions [6], Posner Analysis [46], Kern six steps of developing curriculum [44], SPICES model [47] and bench marking the curriculum against any set criteria such as WFME [48], LCME (Liaison Committee for Medical Education [49] and Tomorrow's doctor 2011 [50]. In this respect where an institute is aiming to diagnose curricular issues, no systematic tool or inventory to measure curricular problems has been reported in the literature. It is important that instruments be developed that measure not only a curriculum's quality but also its viability, enabling stakeholders to obtain a true and comprehensive picture of their curriculum's current health status and to identify the reasons why specific standards have not been met.

\section{Conclusion}

This scoping review explored different standards and inhibitors of curriculum quality. We introduced the term 'curriculum viability' as denoting a curriculum's well-being that can be determined only by considering the degree to which quality standards have been met or not attained as well as the inhibitors affecting the attainment of those standards. We hope that this modified evaluation framework will help identify problems adversely affecting the well-being of a curriculum and remaining hidden or un-noticed when curriculum evaluation is done, thereby contributing to its improvement and innovation.

\section{Additional files}

Additional file 1: (Online Search Strategy). (DOCX 24 kb)

Additional file $\mathbf{2}$ Assessing the quality of articles and Inter-rater agreement. (DOCX 2207 kb)

\section{Abbreviations}

DREEM: Dundee Ready Education Environment Measure; GMC: General Medical Council; LCME: Liaison Committee for Medical Education; WFME: World Federation of Medical Education; WOS: Web of Science

\begin{abstract}
Acknowledgements
None.

Authors' contributions

RAK, AS, UM and JVM concieved and designed the study. RAK did the initial literaure search. RAK and AS performed the thematic analysis. JVM, AS and UM helped in preparing the manuscript by providing repititive feedbacks. All authors read and approved the final manuscript.
\end{abstract}

\section{Authors' information}

Rehan Ahmed Khan is an Assistant Dean Medical Education and Prof. of Surgery in Riphah International University, Pakistan. His interests include curriculum innovation, implementation and evaluation. He has done master's in medical education from University of Glasgow and is currently a PhD scholar in medical education in Maastricht University. ORCiD https://orcid.org/0000-0002-8045-1471.

Annemarie Spruijt is an Assistant professor at Utrecht University who has a background in veterinary medicine and did her PhD in medical and veterinary education. She takes a special interest in curriculum design, improving the quality of medical and veterinary education and in small-group learning. ORCiD A Spruijt https://orcid.org/0000-0002-0995-5503. Usman Mahboob is Director of the Institute of Health Professions Education \& Research (IHPER) at the Khyber Medical University, Pakistan. $\mathrm{He}$ is a medical doctor by professions and did his doctorate in health professions education from the University of Glasgow, UK. His research interests are professionalism, approaches to teaching and learning, and curriculum development. ORCiD https://orcid.org/0000-0002-4756-6787. Jeroen J. G. van Merrienboer is full professor of Learning and Instruction and Research Director of the School of Health Professions Education at Maastricht University, the Netherlands. His research focuses on instructional design, the use of ICT in education, and the development of professional competencies. ORCID is: https://orcid.org/0000-0002-5868-7031.

Funding

There was no funding or grants from any source for the study.

Availability of data and materials

The data generated and analysed during the study are through research articles that have been referenced and can be accessed through the reference list.

Ethics approval and consent to participate

This study is a scoping review (type of literature review). This study does not report or involve any human or animal data or tissue. (Not Applicable).

\section{Consent for publication}

Not applicable.

\section{Competing interests}

Dr. Usman Mahboob (co-author) is a member of the editorial board of BMC Medical Education. The remaining authors declare that they have no competing interests.

\section{Author details}

${ }^{1}$ Islamic International Medical College, Riphah International University, Al-Mizan IIMCT Complex, Old Supreme Court Building, 274 Peshawar Rd, Rawalpindi, Pakistan. ${ }^{2}$ School of Health Professions Education, Maastricht University, Maastricht, The Netherlands. ${ }^{3}$ Faculty of Veterinary Medicine, Utrecht University, Utrecht, The Netherlands. ${ }^{4}$ Institute of Health Professions Education and Research, Khyber Medical University, Peshawar, Pakistan. ${ }^{5}$ Centre for Medical Education, University of Dundee, Dundee, UK. 
Received: 31 May 2019 Accepted: 19 August 2019 Published online: 05 September 2019

\section{References}

1. Bosco J. Curriculum theory. Educ Forum. 1971;35:259-60.

2. Taylor DCM, Hamdy H. Adult learning theories: implications for learning and teaching in medical education: AMEE Guide No. 83. Med Teach. 2013;35:e1561-72.

3. Prideaux $D . A B C$ of learning and teaching in medicine. Curriculum design. BMJ (Clinical research ed). 2003;326:268-70.

4. Aliyeva E. An overview of the national curriculum development process for Azerbaijan. Online J New Horizons Educ. 2016;6:13-26.

5. Walker D. A naturalistic model for curriculum development. School Rev. 1971;80:51-65

6. Harden RM, Education CM. Ten questions to ask when planning a course or curriculum. Med Educ. 1986;20:356-65.

7. Bansal S, Bansal A, Dalrymple O. Outcome-based Education model for computer science Education. J Eng Des. 2015;28:113-21.

8. Miner A, Mallow J, Theeke L, Barnes E. Using Gagne's 9 events of instruction to enhance student performance and course evaluations in undergraduate nursing course. Nurse Educ. 2015;40:152-4.

9. Vandewaetere M, Manhaeve D, Aertgeerts B, Clarebout G, Van Merriënboer JJG, Roex A. 4C/ID in medical education: How to design an educational program based on whole-task learning: AMEE Guide No. 93. Med Teach 2014;37:1-17.

10. Harden RM. AMEE guide no. 21: curriculum mapping: a tool for transparent and authentic teaching and learning. Med Teach. 2001;23:123-37.

11. Nelson M, Jacobs C, Cuban L. Concepts of curriculum. Teach Learn Med. 1992:4:202-5.

12. Mcleod P, Steinert $Y$. Twelve tips for curriculum renewal. Med Teach 2015;37:232-8

13. American Diabetes Association. 2016 American Diabetes Association (ADA) diabetes guidelines summary recommendation from NDEl. Natl Diabetes Educ Initiat. 2016;39:1-46.

14. Tackett S, Grant J, Mmari K. Designing an evaluation framework for WFME basic standards for medical education. Med Teach. 2015;38:1-6.

15. Abrahamson S. Diseases of the curriculum. J Med Educ. 1978:53:951-7.

16. Rezaeian M, Jalili Z, Nakhaee N, Jahroomi Shirazi J, Jafari AR. Necessity of accreditation standards for quality assurance of medical basic sciences. Iran J Public Health. 2013;42:147-54.

17. MacCarrick G, Kelly C, Conroy R. Preparing for an institutional self review using the WFME standards an international medical school case study. Med Teach. 2010;32:e227-32.

18. Abdalla ME. Social accountability of medical schools: do accreditation standards help promote the concept? J Case Stud Accred Assess. 2014;3:1-12.

19. Geffen L, Cheng B, Field M, Zhao S, Walters T, Yang L. Medical school accreditation in China: a Sino-Australian collaboration. Med Teach. 2014;36:973-7.

20. Al-Shehri AM, Al-Alwan I. Accreditation and culture of quality in medical schools in Saudi Arabia. Med Teach. 2013;35:S8-14

21. Whalen JP, Cerchio G, Muslin H. Quality assurance for a medical school curriculum. Teach Learn Med. 1990;2:42-5.

22. World Federation for Medical Education. Basic Medical Education WFME Global Standards for Quality Improvement http://wfme.org/publications/ wfme-global-standards-for-quality-improvement-bme/?wpdmdl=831. 2015.

23. Arthur C, Levett-Jones T, Kable A. Quality indicators for the design and implementation of simulation experiences: a Delphi study. Nurse Educ Today. 2013;33:1357-61.

24. Mooney CJ, Lurie SJ, Lyness JM, Lambert DR, Guzick DS. Development of an audit method to assess the prevalence of the ACGME's general competencies in an undergraduate medical Education curriculum. Teach Learn Med. 2010;22:257-61

25. Executive Council WF for ME, The Executive Council WFME. International standards in medical education: assessment and acccreditation of medical schools' - educational programmes. A WFME position paper. Med Educ. 1998:32:549-58

26. Sargeant JM, Pham MT, McEwen SA, Greig JD, Rajić A, Papadopoulos A. A scoping review of scoping reviews: advancing the approach and enhancing the consistency. Res Synth Methods. 2014;5:371-85.
27. Arksey H, O'Malley L. Scoping studies: towards a methodological framework. Int J Soc Res Methodol: Theory Prac. 2005:8:19-32.

28. Haddaway NR, Collins AM, Coughlin D, Kirk S. The role of google scholar in evidence reviews and its applicability to grey literature searching. Wray KB, editor. PLoS One. 2015;10:e0138237.

29. Haig A, Dozier M. BEME guide no. 3: systematic searching for evidence in medical education--part 2: constructing searches. Med Teach. 2003;25:463-84.

30. Kmet, L.M., Lee, R.C. and Cook LS. Standard Quality Assessment Criteria for Evaluating Primary Research Papers https://archive.org/details/ standardqualitya00kmet_0. 2004.

31. Diamond JJ. Cohen's kappa. J Clin Epidemiol. 1991:44:609.

32. Sharma R, Gordon M, Dharamsi S, Gibbs T. Systematic reviews in medical education: a practical approach: AMEE guide 94. Med Teach. 2015;37:10824

33. Chaney BH, Eddy JM, Dorman SM, Glessner LL, Green BL, Lara-Alecio R. A primer on quality indicators of distance education. Health Promot Pract. 2009;10:222-31.

34. Sae-Khow J. Developing of indicators of an E-learning benchmarking model for higher education institutions. Turk Online J Educ Technol. 2014;13:35-43.

35. Njiro E. Understanding Quality Culture in Assuring Learning at Higher. J Educ Policy Entrep Res. 2016;3:79-92.

36. Pugsley L, Brigley S, Allery L, Macdonald J. Counting quality because quality counts: differing standards in master's in medical education programmes. Med Teach. 2008:30:80-5.

37. Ryan P. Quality Assurance in Higher Education: a review of the literature. High Learn Res Commun. 2015:5:1-15.

38. Roff SUE, Mcaleeri S, Harden RM, Al-qahtani M, Uddin A, Deza H, et al. Development and validation of the Dundee ready Education environment measure ( DREEM ). Med Teach. 1997;19:295-9.

39. Damen A, Remmen R, Wens J, Paulus D. Evidence based post graduate training. A systematic review of reviews based on the WFME quality framework. BMC Med Educ. 2011;11:80.

40. Al-Subait R, Elzubeir M. Evaluating a masters of medical education program: attaining minimum quality standards? Med Teach. 2012;34:S67-74.

41. van Zanten M, Boulet JR, Greaves I. The importance of medical education accreditation standards. Med Teach. 2012;34:136-45.

42. Bendermacher GWG, Egbrink MGA o, IHAP W, DHJM D. Unravelling quality culture in higher education: a realist review. High Educ. 2017;73:39-60.

43. Olson BG, Mata M, T a K. Implementing an Online Curriculum for Medical Education: Examining the Critical Factors for Success. Int J E-Learning. 2013;12:197-208.

44. Kern D, Thomas P, Hughes M. Curriculum development for medical education: a six-step approach. Baltimore: JHU Press; 2016.

45. Harden RM. AMEE guide no. 21: curriculum mapping: a tool for transaprent and authentic teaching and learning. Med Teach. 2001;23:123-37.

46. Posner GJ. Analyzing the curriculum. 3rd ed. New York: Mc Graw Hill; 2004. p14.

47. Harden RM, Sowden S, Dunn WR. Educational strategies in curriculum development: the SPICES model. Med Educ. 1984;18:284-97.

48. MacCarrick G, Kelly C, Conroy R. Preparing for an institutional self review using the WFME standards An International Medical School case study. Med Teach. 2010;32:e227.

49. Karle H. Global standards and accreditation in medical education: a view from the WFME. Acad Med. 2006;81:s43-8.

50. Knight K, Whybra N, Wright R. Fitness for practice: how can junior doctors ensure they keep up to date? Br J Surg. 2015;102:212-3.

\section{Publisher's Note}

Springer Nature remains neutral with regard to jurisdictional claims in published maps and institutional affiliations. 